\title{
Article
}

\section{Articulating Scientific Reasoning Improves Student Learning in an Undergraduate Anatomy and Physiology Course}

\author{
Johanna Krontiris-Litowitz \\ Department of Biological Sciences, Youngstown State University, Youngstown, OH 44555
}

Submitted November 18, 2008; Revised June 12, 2009; Accepted June 24, 2009

Monitoring Editor: Christopher Watters

\begin{abstract}
In many life science classrooms, instructors rely upon lecture presentations to efficiently present course content. Students, in this case, act as passive learners with little opportunity to test their knowledge for gaps or misconceptions. The goal of the project described here was to determine whether a collaborative quiz protocol that guided students to discuss their understanding with their peers would improve learning and academic performance. The project took place during a single semester and was composed of two studies: a preliminary study that incorporated short-answer quizzes into the curriculum and a comprehensive study that incorporated short-answer quizzes and justify/explain quizzes in which students were expected to select an answer and then justify or explain it. Students took all quizzes twice, first independently and then collaboratively with classmate(s). Learning was assessed using multiple-choice exam questions based upon quiz topics. Students scored significantly higher on exam questions associated with justify/explain quiz topics than on those associated with short-answer quiz topics.
\end{abstract}

\section{INTRODUCTION}

In information-intensive classrooms such as those found in the life sciences, instructors rely upon lecture presentations to efficiently present course content and concepts to students. This is considered an especially effective method of dissemination in a high enrollment class. Instructors often try to accommodate student anxieties about the course material by investing much effort into preparing clear, thorough, and well-annotated presentations. In return, students attend classes, conscientiously take notes, and then return home to learn the material by memorization and practice. However, while using these learning strategies, students have little opportunity to challenge their knowledge; thus, they are more likely to retain gaps in their knowledge base and incorporate misinformation or misconceptions into their understanding. The end result is that frequently student learning is compromised, and students may not be able to readily solve problems, explain their reasoning, or apply their knowledge to new situations. One remedy to this sit-

DOI: $10.1187 /$ cbe.08-11-0066

Address correspondence to: Johanna Krontiris-Litowitz (jkrontirislitowitz@ysu.edu). uation is to take advantage of student presence in the classroom during the lecture hour and create activities that engage the student in learning.

Active learning, broadly defined as engaging students in the learning process, is a well-established and highly regarded instructional method that has applications both inside and outside the classroom. The instructional activities associated with active learning are diverse and include traditional assignments such as homework and term papers as well as more contemporary assignments such as team assessments, manipulative tasks, and case studies (Michael, 1993; Krontiris-Litowitz, 2003; Prince, 2004; Guiliodori et al., 2006). Active learning can be enhanced when it incorporates peer sharing of knowledge and understanding. Collaborative learning, cooperative learning, and problem-based learning are all well-documented, successful forms of active learning that are based upon peer interaction and peer teaching (Bonwell and Eison, 1991; Bosworth and Hamilton, 1994).

Collaborative learning has been shown to be effective not only in improving academic achievement and increasing retention but also in developing group behaviors and personal skills that promote individual and team learning (Johnson et al., 1998a,b). Essentially, these behaviors are acquired and exhibited during collaborative group discus- 
sions and are integral to the success of the discussion (McKeachie, 1972; Cabrera et al., 2002). Accountability behavior, a fundamental of collaborative learning, charges team members to be responsible for the learning process. Students engage in accountability behavior as individuals when they are held responsible for the information and tasks that they share with their group. They also engage in this behavior at a group level, when they, as members of the collaborative group, evaluate cumulative group learning, assess its accuracy, or challenge its validity by comparing it against their own knowledge framework.

The student discussion embedded in collaborative activities has a value in the learning process that extends beyond the collaborative group behaviors that it provokes. Discussion inherently involves talking, and talking advances learning. Thus, discussions provide students with a venue where they can engage in verbal behaviors that promote learning. As students speak in discussions, they are able to confirm their information, fit their understanding with what they already know, and challenge their own ideas (Glaserfeld, 1989; Rivard and Straw, 2000; Guiliodori et al., 2006; Desrochers et al., 2007). Frequently, when students engage in a discussion, they verbalize ideas that are beyond the boundaries of their knowledge and in this way engage in intellectual risk taking. This behavior is particularly valuable because the risk is founded on the student's conceptual understanding of the topic and causes the student to review and reexamine their understanding. Finally, talking is a key step in retention, and by teaching what one knows to other students, one is better positioned to establish pathways for long-term memory (Bonwell and Eison, 1991; Yager, 1991; Lundberg and Moch, 1995).

An extensive body of literature indicates that writing activities enhance learning and that frequent writing activities seem to have a cumulative effect on learning. In studies in which writing was incorporated into the curriculum as a recurrent activity, instructors observed a progression of student understanding such that over time, students were able to transform rudimentary ideas about science into coherent, structured science knowledge, express a more organized rationale in their justifications, and develop explanations that were closer to accepted scientific explanations. (Fellows, 1994; Rivard and Straw, 2000). Research has shown that the learning value of writing depends on the structure and implementation of the assignment. Effective writing assignments guide student thinking, prompt students to explain their reasoning, promote reflection on content, encourage students to develop processing skills, and demand that students organize their ideas and rationale. Well-constructed writing assignments seem to pay off. Studies show that they generate critical thinking, promote better understanding and recall, enable students to identify misconceptions, and engage students in a way that generates new knowledge. Finally, students recognize the value of writing and have reported that reflective writing provides a structure that enables them to determine what they do not understand (Strauss and Fulwiler, 1990; Moore, 1993, 1994; Fellows, 1994; Rivard, 1994; Rivard and Straw, 2000; Hohenshell and Hand, 2006; Kalman et al., 2008).

Some educators have suggested that a learning synergy develops when students are able to combine talking with writing about a topic. They argue that talking, by itself, presents a flexible form of discourse for students that can accommodate the maximal amount of innovation and creativity with minimal participant effort. Conversely, they contend that writing represents a discourse in which the participant must invest heavily, be relatively focused, and not get detoured by spontaneous or unrelated ideas. Together, however, talking and writing can provide a learning environment that encourages innovation while requiring sound processing and organization of knowledge. Studies support this idea and show that when students are able to combine writing about a topic with discussion they exhibit greater retention, more productive cognitive processing, and broader conceptual understanding than they do with either writing or talking alone (Fellows, 1994; Rivard and Straw, 2000).

This project was designed to address problems encountered in an undergraduate Anatomy and Physiology course. The course is an introductory information-intensive highenrollment course and was typically taught in a lecture format with little opportunity for student engagement or active learning. Students perceived the course as a memorization course and used this technique to study for exams. Students did not do well on exams and frequently were unable to answer case study-type questions, solve problems, or explain their reasoning for an answer. The goal of the project was to determine whether a collaborative quiz protocol, which guided students to discuss their understanding with their peers, would improve academic performance.

\section{METHODS}

This project evaluated the effect of articulation on student learning in a one-semester undergraduate course in Human Anatomy and Physiology (A\&P) at a mid-sized midwestern university. Students in the course were enrolled in a variety of health science majors (e.g., dental hygiene, emergency medical technology, and radiology) and education majors. The project took place during a single semester and was composed of two studies: a preliminary study and a comprehensive study. In the preliminary study, the instructor incorporated short-answer quizzes into the curriculum to assess student understanding of lecture material. The outcomes of the preliminary study guided the design of the second, comprehensive study that incorporated both short-answer quizzes and justify/ explain quizzes into the curriculum and then assessed their effect on learning. In the preliminary study, which occurred during the initial part of the semester, students took a series of three quizzes composed of short-answer questions (multiple-choice or fill-in-theblank questions). In the second study protocol, which took place in the subsequent part of the semester, students took a series of quizzes that assessed their understanding of lecture material. The quizzes were composed of short-answer questions or justify/explain questions in which students were expected to select an answer and then write several sentences justifying, describing, or explaining their response. The instructor selected two fundamental topics from the material associated with each exam and used these to create quiz questions. One topic served as the basis for short-answer quiz questions and the other topic served as the basis for justify/explain quiz questions. Combined quiz grades (perfect score) represented $6-8 \%$ of the exam grade and were considered bonus points. Student learning was assessed using multiple-choice exam questions. Each exam covered the topic associated with short-answer quiz questions and the topic associated with justify/explain quiz questions as well as other topics. Scores were normalized, mean and SD were calculated, and significance was determined by analysis of variance and the Holm-Sidak pairwise multiple comparisons procedure.

The protocol for administering quizzes was the same for both justify/explain and short-answer quizzes. The class was advised 
Table 1. Preliminary study short-answer quiz question and examples of answers

\begin{tabular}{lll}
\hline Quiz question & \multicolumn{1}{c}{ Correct answer } & $\begin{array}{c}\text { Incorrect/insufficient } \\
\text { answer }\end{array}$ \\
\hline $\begin{array}{c}\text { One function of } \\
\text { the skin is - }\end{array}$ & $\begin{array}{c}\text { Protects against } \\
\text { dehydration } \\
\text { Protects against } \\
\text { infection } \\
\text { Protects against UV } \\
\text { rays }\end{array}$ & Protection \\
& $\begin{array}{l}\text { Protects against injury } \\
\text { Protects against } \\
\text { harmful chemicals } \\
\text { entering body }\end{array}$ & $\begin{array}{l}\text { Replaces scar tissue } \\
\text { Cools body } \\
\text { Excretion }\end{array}$ \\
\hline
\end{tabular}

that there would be a quiz in the next session over identified lecture material, and all students attending were expected to take the quiz. Students took all quizzes twice, first independently, as a formative assessment to inform both the student and the instructor; and then collaboratively with a classmate(s) to promote learning and engagement. The instructor did not assign partners and did not regulate collaboration unless a student tried to work alone. In these few cases, the instructor prodded the student to find a partner and work with him or her to complete the quiz. Student engagement during the quizzes was assessed by instructor observation and by student performance on the quizzes. Scores were normalized, mean and SD calculated, and significance determined using Mann-Whitney rank sum test.

At the end of the course, students were surveyed about teaching strategies used during the semester. Student responses were evaluated using a Likert scale, and written comments were recorded and collated by an independent observer. The protocol for this study (YSU-IRB 1608) was reviewed and approved by the Youngstown State University Human Subjects Committee.

\section{RESULTS}

\section{Preliminary Study Investigating the Effect of Classroom Quizzes on Student Learning}

In the preliminary study, students took several short-answer quizzes that were composed of multiple-choice questions or questions that could be answered with a word or phrase (Table 1). Student participation in quizzes was variable. Six students took only one quiz, and 52 students took all quizzes offered. Student investment in the quizzes was low. Often, students did not answer quiz questions or did not provide thorough answers. In one quiz, only $47.5 \%(n=65)$ of the students answered half or more of the questions on their own. When they took the quiz collaboratively, most students answered all of the questions, but the answers were not complete. For example, when answering the question "One function of the skin is __ $56.9 \%$ of the class responded using only the word "protection." In contrast, $25 \%$ of the class answered the question more thoroughly by explaining the specific types of protection such as "protection from infection, bacteria, UV rays, etc." (Table 1). Student performance on exams 1 and 2 showed that these quizzes did not improve student learning (Table 2). The mean exam scores were not significantly different from mean exam scores recorded in prior years of the course $(p>.05)$.

\section{Justify/Explain Quizzes Improve Learning}

The results of the preliminary study suggested that the short-answer quiz protocol was not sufficient and would need to be modified to enhance learning. Consequently, in a second study, the quiz protocol was revised to include quizzes composed of short-answer questions or justify / explain questions in which students were expected to write three to four sentences justifying or explaining their answer (Table 3).

Student participation in quizzes varied. Fifteen percent of the students who took the final exam took at least one quiz (short-answer or justify/explain) and 35\% took all quizzes offered $(n=60)$. Students were more likely to answer justify/ explain quizzes than short-answer quizzes. Ninety-five percent of the students who took a justify/explain quiz over a cardiovascular topic $(n=44)$ answered all questions, and $85 \%$ of the students who took a justify/explain quiz over a respiratory topic $(n=40)$ answered all questions. Responses were usually complete, including an answer as well as a justification, explanation, etc. Collaborative quizzes yielded a mix of revised correct answers, revised incorrect answers, and unchanged answers (correct and incorrect). Sample answers are shown in Table 3. In contrast, when students took a short-answer quiz over a different cardiovascular topic, only $54.5 \%$ answered all questions $(n=44)$. When students took a short-answer quiz over a different respiratory topic, $77.5 \%$ answered all questions $(n=41)$. Responses to shortanswer quizzes were similar to those reported for the preliminary study. Answers were frequently incomplete and in some cases students did not revise the answers that were incorrect.

Student learning was assessed by performance on a series of three exams (exams 4, 5, and 6) composed of questions covering topics from justify/explain and short-answer quizzes, as well as other lecture topics (Table 4). The mean score for each exam was not significantly different from

Table 2. Student exam performance for preliminary study with short-answer quizzes

\begin{tabular}{|c|c|c|c|c|c|}
\hline \multicolumn{2}{|c|}{ Exam 1} & \multicolumn{2}{|c|}{ Exam 2} & \multicolumn{2}{|c|}{ Exam 3} \\
\hline Preliminary study & Prior yr & Preliminary study & Prior yr & Preliminary study & Prior yr \\
\hline $69.4 \pm 1.0(80)$ & $73.7 \pm 1.2(67)$ & $70.2 \pm 1.3(69)$ & $69.6 \pm 1.4(65)$ & $70.9 \pm 1.2(59)$ & $68.4 \pm 1.3(63)$ \\
\hline
\end{tabular}


Table 3. Comparison of individual and collaborative answers of justify/explain quiz

Question

Mary is pregnant with her second child. Mary is Rh negative. During the pregnancy the fetus develops erythroblastosis fetalis where the red blood cells (RBC) are destroyed by the mother's antibodies to the $\mathrm{Rh}$ factor. Both babies have the same father. Is he $\mathrm{Rh}+, \mathrm{Rh}-$, or neither? Explain your answer

Incorrect answer after first quiz

\section{$\mathrm{Rh}-: \mathrm{b} / \mathrm{c}$ when the mother and father both have the same Rh factors they can not coexist with each other and that causes problems}

$\mathrm{Rh}-$ : because the baby is $\mathrm{Rh}-$ and mother is trouble producing $\mathrm{Rh}-\mathrm{RBC}$

$\mathrm{Rh}+: \mathrm{b} / \mathrm{c}$ it is the same father and the mother is $\mathrm{Rh}-$
$\mathrm{Rh}+$ : the gene carried by the male
The father is $\mathrm{Rh}-\mathrm{b} / \mathrm{c}$ Mary was positive so they change that the baby had came from the father
$\mathrm{Rh}-\mathrm{b} / \mathrm{c}$ the baby is $\mathrm{Rh}+$; does not have ...
The father is $\mathrm{Rh}+$ but more dominant
$\mathrm{Rh}+$ : not exactly sure why
Neither, he doesn't affect the child
$\mathrm{Rh}+$ : gene needed to be placed in mother in order for erythroblastosis to occur in child
$\mathrm{Rh}+$ : if the second baby's DNA was rejected so to speak it means that the father's genes were dominant in the baby and he is $\mathrm{Rh}+$

Answer after collaborative quiz

$\mathrm{Rh}+$ : baby gets from mother's body; reject the $\mathrm{Rh}+$ because she is $\mathrm{Rh}-$

$\mathrm{Rh}+\mathrm{b} / \mathrm{c}$ he caused the baby to have $\mathrm{Rh}+$ blood

$\mathrm{Rh}+$ : because during the (first) baby, the body started producing antibodies but not long enough to destroy the baby

$\mathrm{Rh}+\mathrm{b} / \mathrm{c}$ mother is $\mathrm{Rh}-$ and baby is $\mathrm{Rh}+$

$\mathrm{Rh}+\mathrm{b} / \mathrm{c}$ she is $\mathrm{Rh}-$

$\mathrm{Rh}+$ : because of dominance

No change

No change

No change

No change

No change the preliminary study or from previous years (Table 5). Class performance on justify/explain topic questions and short-answer topic questions was analyzed independently, and no significant difference in exam performance was observed.

The exam data were reanalyzed to see whether students who took the quizzes scored differently on exams from those who did not take quizzes. Exam scores of students who took quizzes were significantly higher than the exam scores of the students (Table 6) who took none or one quiz for exam 4 and exam 6 ( $p=.007$ and $p<.001$, respectively) and but not for exam $5(p=.085)$.

Further analysis of students who took class quizzes indicated that their exam performance was influenced by the type of quiz that they took (Table 7). Students who took class quizzes scored significantly higher on justify/explain topic questions than on short-answer topic questions on exam 4 and exam $5(p<.05)$ but not on exam 6 . By the end of the semester, students seem to be doing better on the justify/ explain questions than on the rest of the exam (Table 6). Initially on exam 4, students scored better on remaining test questions. However, in exams 5 and 6 student scores on justify/explain questions were significantly higher than they we on the remaining test questions $(p<.05)$. Finally, exam performance on short-answer topic questions was similar to that observed in the preliminary study and was not significantly different from the scores reported in Table 1.

\section{Instructor Observation of Student Engagement and Attitude toward Quizzes}

In the preliminary study, students engaged with their classmates in the collaboration discussion phase of the quiz pro- tocol. During these discussions, the instructor observed students conferring with neighbors and asking each other about their respective answers. These discussions, however, were short and lacked extended conversation. When there was a conflict among students regarding the answer to a question, students usually deferred to an authoritative justification. For example, a student might defend his/her answer with "She said in the last lecture that..." or "The book said that ...."

In the second phase of the study in which both justify/ explain and short-answer quizzes were administered, the instructor observed students conferring with neighbors during the collaborative phase of both quiz protocols, asking each other about their respective answers. During justify/explain quizzes the discussion was protracted and animated with students occasionally engaging the instructor to advise or arbitrate differing ideas. When there was a conflict among students regarding the answer to a question, students often deferred to their written explanation saying, "I wrote that calcium was elevated because of negative feedback through ...." Typically, the student's defense of his or her answer incorporated a physiological concept and the reason for using it. Student discussions often extended beyond a single quiz partner; and by the end of the study, many discussion groups incorporated four to six students.

Many students embraced the quizzes and perceived them as a formative assessment tool. In an end-of-course survey, students were asked, "What aspect of the course was valuable and should not be changed in future courses?" More than $20 \%$ of the students surveyed answered this question by discussing the collaborative quizzes. The majority of these students $(82.5 \%)$ felt that class quizzes should remain in the curriculum, but they did not discriminate between the 
Table 4. Examples of quiz questions and exam questions

Quiz question

What do the dorsal respiratory neurons regulate?

Shown below is a capillary in the lung.

Where is the $\mathrm{PCO}_{2}=40 \mathrm{~mm} \mathrm{Hg}$ ?

Where is $\mathrm{PCO}_{2}=45 \mathrm{~mm} \mathrm{Hg}$ ?

Answer A, B, or C.

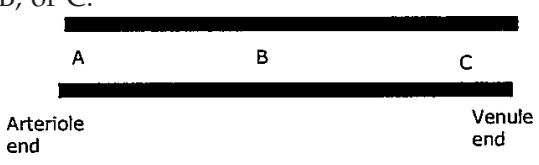

Jake has blood type "A." Can he donate to

1. AB Why?

2. O Why?

Mary is pregnant with her second child. Mary is Rh-. During the pregnancy, the fetus develops erythroblastosis fetalis where the red blood cells (RBC) are destroyed by the mother's antibodies to the $\mathrm{RH}$ factor.

The fetus is: $\mathrm{Rh}+, \mathrm{Rh}-$, neither

Explain your answer.

List 3 ways that the body stops bleeding.

What hormone causes the liver to break down glycogen into glucose? What hormone causes the liver to store glucose as glucagon?
Correlating exam question

There can be $0,1,2$, or 3 correct answers to the question.

Harold is taking notes in A\&P class. What controls his breathing rate at this time?

1. dorsal respiratory neurons

2. pneumotaxic center

3. sternocleidomastoid contraction

Samir has been playing soccer for the last $40 \mathrm{~min}$ and his $\mathrm{PCO}_{2}$ has increased. The diagram below shows a capillary in the alveoli. Where will the $\mathrm{PCO}_{2}$ levels increase in the alveoli? 1. A

2. B

3. C

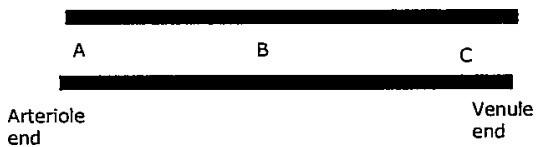

Elise is in an accident and needs a transfusion. She has type $A B$

blood. Which of the following people can act as donors?

1. Uncle Herbert with type A blood

2. Aunt Sissy with type B blood

3. Cousin Vince with type O blood

Maya is going to have her first baby. May is Rh+ and the baby's father is $\mathrm{Rh}-$. Which of the following is(are) true about the fetus?

1. the fetus will develop erythroblastosis fetalis

2. the fetus will not develop erythroblastosis

3. the fetus must be $\mathrm{Rh}+$

Louis has cut his arm. Which of the following will stop bleeding at the wound?

1. a decrease in heart rate

2. a platelet plug

3. a vasospasm

Mary was late this morning so she skipped breakfast. At noon, Joe asked her to help him study for an A\&P exam so she skipped lunch and reviewed the endocrine system until she went to her exam. Which of the following might be elevated when she took her exam?

1. insulin

2. glucagon

3. cortisol

There were 50 multiple-choice questions on each exam. Questions were scrambled to create three equivalent versions of the each exam.

justify/explain or the short-answer quizzes. Their responses included comments such as the following:

"... the quizzes taken twice so you can see how well you did then once realizing what you got wrong, you can fix it."

"...the quizzes in class where we talked to other students."

"... I liked the quizzes. Overall it was better than sitting in lecture."

"... the second part of the quizzes because it helped me learn and figure out if I had the right answer."

"...going over the quizzes (with partners) after we did them ourselves."

The remaining respondents did not like the class quiz format and cited this as one aspect of the course that should be changed. Student comments such as the comment below suggested that some students may need training in the skills that make group activities productive for learning.

"I was more confused listening to others. I don't like working with others."

This group of students did not view the quizzes as formative exercises but rather saw them as a means of acquiring points, suggesting that the instructor may need to enlighten students about the formative assessment aspect of class quizzes.

\section{DISCUSSION}

Although a significant body of literature contends that articulation of science enhances student learning and under- 
Table 5. Exam scores after justify/explain and short-answer quizzes

\begin{tabular}{lcr}
\hline Exam 4 & Exam 5 & Exam 6 \\
\hline $67.6 \pm 9.7(61)$ & $68.4 \pm 8.8(58)$ & $65.6 \pm 9.7(60)$ \\
\hline $\begin{array}{l}\text { Values are mean exam score } \pm \text { SD (\%). Numbers in parentheses are } \\
\text { number of students. }\end{array}$ \\
\hline
\end{tabular}

standing of science, few studies provide quantitative data substantiating this claim. This article presents quantitative data that show that articulation associated with the justify/ explain quiz protocol improved learning and was more effective than the alternative short-answer quiz protocol. The short-answer quiz, a familiar and frequent assessment in the classroom, was modified in this study to include a collaborative learning component in which students discussed their answers after the quiz. In spite of the collaborative component, this formative assessment did not improve student exam performance.

One might argue that students who took the quizzes represent the stronger students who should do better on exams. These students by virtue of attending class would have the benefit of a class lecture to help them understand future quiz topics as well as the additional review/practice when taking the quiz. Classroom research as well as instructor experience suggests that attendance is often a predictor for student performance and that students who attend class are often more responsible about studying than their "no show" counterparts and therefore would already be better students. The short-answer quiz analysis addresses these issues. Those students who took short-answer quizzes attended classes and benefited from class lectures and additional practice through quizzes. However, these students did not significantly improve their exam performance nor did they score significantly better on quiz-associated questions than their "no-quiz" peers.

The success of the justify/explain quiz can be attributed to several factors. First, our data indicate that requiring students to articulate their understanding for every response by justifying or explaining their answer seemed to be key to enhancing learning. This is consistent with studies reported by Moore $(1993,1994)$ that showed that writing assignments in the science classroom did not pro-
Table 7. Exam analysis for students who took quizzes

\begin{tabular}{lccc}
\hline & Exam 4 & Exam 5 & Exam 6 \\
\hline $\begin{array}{l}\text { Questions related to } \\
\text { justify/ explain quiz } \\
\text { topics } \pm \text { SE (\%) }\end{array}$ & $63.2 \pm 12.2^{*+}$ & $77.7 \pm 17.3^{*+}$ & $75.6 \pm 13.6^{+}$ \\
$\begin{array}{c}\text { Questions related to } \\
\text { short-answer quiz } \\
\text { topics } \pm \text { SE (\%) }\end{array}$ & $56.2 \pm 13.6$ & $67.2 \pm 10.5$ & $66.3 \pm 13.7$ \\
$\begin{array}{l}\text { Remaining questions } \pm \\
\text { SE (\%) }\end{array}$ & $72.3 \pm 10.6$ & $69.5 \pm 8.9$ & $66.7 \pm-8.9$ \\
$\mathrm{n} \quad$ & 34 & 45 & 28 \\
\hline
\end{tabular}

${ }^{*} p<0.05$, justify/explain versus short answer; ${ }^{+} p<0.05$, justify/ explain versus remaining.

$p<0.05$, short answer versus justify/explain for exam 4; $p>0.05$ short answer versus justify/explain for exams 5 and 6 .

duce real learning unless they incorporated questions or scaffolds that elicited articulation of scientific process or understanding in the answer.

Second, the results from this study suggest that the justify/ explain protocol promoted student engagement and investment in learning in the classroom. Student participation in short-answer quizzes in both the preliminary and comprehensive studies was poor, and the majority of students did not bother to answer questions during the first presentation of the quiz. In contrast, students seemed to be more engaged during the justify/explain quizzes, typically answering nearly all of the questions on the first trial.

A third factor of the justify/explain quizzes that contributed to student success was related to the level at which peers shared knowledge. In the short-answer quiz, students were simply expected to share their knowledge with their partners in the collaboration phase of the activity. However, in the justify/explain protocol students needed to do more than just distribute knowledge during their collaborative discussions; they were expected share the processing or reasoning that they used to arrive at it. In this way, the writing component complemented the discussion behaviors of collaborative learning. Students who shared their knowledge were also accountable for their knowledge as they justified and explained it. In turn, group members had the opportunity to challenge the knowledge presented and test its fit against their individual understanding.

Table 6. Exam scores: students who took quizzes versus students who did not take quizzes

\begin{tabular}{|c|c|c|c|c|c|c|}
\hline & \multicolumn{2}{|c|}{ Exam 4} & \multicolumn{2}{|c|}{ Exam 5} & \multicolumn{2}{|c|}{ Exam 6} \\
\hline & Took quizzes & No quiz & Took quizzes & No quiz & Took quizzes & No quiz \\
\hline Skewedness & $\begin{array}{c}71.7 \pm 10.2^{*}(34) \\
-0.1205\end{array}$ & $\begin{array}{l}64.3 \pm 7.7(27) \\
\quad+0.2849\end{array}$ & $\begin{array}{c}69.3 \pm 8.7^{+}(45) \\
+0.0443\end{array}$ & $\begin{array}{l}64.0 \pm 7.6(13) \\
\quad+0.7196\end{array}$ & $\begin{array}{c}70.0 \pm 1.7^{\ddagger}(28) \\
+0.0971\end{array}$ & $\begin{array}{c}63.0 \pm 1.5(32) \\
+0.3070\end{array}$ \\
\hline
\end{tabular}

The "no-quiz" group took none or one of the quizzes offered for that exam. The "took-quiz" group took all quizzes offered for that exam. There were 50 multiple-choice questions on each exam. Questions were scrambled to create three equivalent versions of the each exam. Values are mean exam score $\pm \mathrm{SD}(\%)$. Numbers in parentheses are number of students.

Quiz versus no quiz: ${ }^{*} p=0.007,{ }^{+} p=0.085$, and ${ }^{\ddagger} p<0.0001$. 
Another factor that contributed to successful learning was the student reflection incorporated into the justify and explain clause. This writing component of the protocol provided students with the opportunity for metacognitive reflection where they could reflect on their knowledge, organize their ideas, and clarify their reasoning (Moore, 1994). Researchers have reported that in some cases, reflective writing causes students to confront what they do not understand through mental dialogue, and encourages them to establish a dialogue between their prior knowledge and their newly acquired knowledge (Kalman et al., 2008).

Finally, these studies and the work of others suggest that there is a kind of learning synergy between writing and speaking and that when combined, as in the case of the justify/explain quizzes, the two promote learning and increase academic performance to a greater degree than either alone (Strauss and Fulwiler, 1990; Liss and Hanson, 1993; Fellows, 1994; Keys, 1999; Rivard and Straw, 2000). Thus, the results of this study suggest that formative assessment and collaborative learning activities alone are not sufficient to improve learning if they are not crafted to incorporate metacognitive processing.

\section{ACKNOWLEDGMENTS}

I thank John Bell and Bill Bradshaw for advice and support throughout this project. The contents of this article were developed under grant P116B041238 from the Department of Education (Fund for the Improvement of Postsecondary Education). However, the contents do not necessarily represent the policy of the Department of Education and endorsement by the federal government should not be assumed.

\section{REFERENCES}

Bonwell, C. C., and Eison, J. A. (1991). Active Learning: Creating Excitement in the Classroom. Report No. 1, Washington, DC: George Washington University.

Bosworth, K., and Hamilton, S. J. (1994). Collaborative Learning: Underlying Processes and Effective Techniques: New Directions for Teaching and Learning, San Francisco, CA: Jossey Bass.

Cabrera, A. F., Crissman, J. L., Bernal, E. M., Nora, A., Terenzini, P. T., and Pascarella, E. T. (2002). Collaborative learning: its impact on college students' development and diversity. J. Coll. Stud. Develop. $43,20-34$.

Desrochers, M., Fink, H., Thomas, A., Kimmerling, J., and Tung, W. (2007). Student assessment: a comparison of solitary, cooperative, and competitive Testing. Int. J. Teach. Learn. High. Educ. 19, 289296.
Fellows, N. (1994). A window into thinking: using student writing to understand conceptual change in science learning. J. Res. Sci. Teach. 31, 985-1001.

Glaserfeld, E. (1989). Cognition, construction of knowledge and teaching. Synthesis 80, 121-140.

Guiliodori, M., Lujan, H., and DiCarlo, S. (2006). Peer instruction enhanced student performance on qualitative problem-solving questions. Adv. Physiol. Educ. 30, 168-173.

Hohenshell, L., and Hand, B. (2006). Writing-to-learn strategies in secondary school cell biology: a mixed method of study. Int. J. Sci. Educ. 28, 261-269.

Johnson, D., Johnson, R., and Smith, K. (1998a). Active Learning: Cooperation in the College Classroom, 2nd ed., Edina, MN: Interaction Book Co.

Johnson, D., Johnson, R., and Smith, K. (1998b). Cooperative learning returns to college: what evidence is there that it works? Change $30,26-35$.

Kalman, C., Aulls, M. W., Rohar, S., and Goodley, J. (2008). Students' perceptions of reflective writing as a tool for exploring an introductory textbook. J. Coll. Sci. Teach. 37, 74-81.

Keys, C. (1999). Revitalizing instruction in scientific genres: connecting knowledge production with writing to learn in science. Sci. Educ. 83, 115-130.

Krontiris-Litowitz, J. (2003). Using manipulatives to improve learning in the undergraduate curriculum. Adv. Physiol. Educ. 27, 109 119.

Liss, J., and Hanson, S. (1993). Writing-to-learn in science. The variables that influence success. J. Coll. Sci. Teach. 22, 342-345.

Lundberg, M., and Moch, S. (1995). Influence of social interaction on cognition: connected learning in science. J. High. Educ. 66, 312-335.

McKeachie, E. (1972). Research on college teaching. Educ. Perspect. 11, 3-20.

Michael, J. (1993). Teaching problem solving in small groups. Ann. N. Y. Acad. Sci. 701, 47-48

Moore, R. (1993). Does writing about science improve learning about science. J. Coll. Sci. Teach. 22, 212-217.

Moore, R. (1994). Writing to learn biology. Let's stop neglecting the tool that works best. J. Coll. Sci. Teach. 23, 289-295.

Prince, M. (2004). Does active learning work? A review of the research. J. Eng. Educ. 93, 223-231.

Rivard, L. (1994). A review of writing to learn in science: implications for practice and research. J. Res. Sci. Teach. 32, 969-983.

Rivard, L., and Straw, S. (2000). The effect of talk and writing on learning science: an exploratory study. Sci. Educ. 84, 566-593.

Strauss, M., and Fulwiler, T. (1990). Writing to learn in large lecture classes. J. Coll. Sci. Teach. 19, 158-163.

Yager, R. (1991). The constructivist learning model; toward real reform in science education. Sci. Teach. 9, 53-57. 